\title{
La determinación del contenido en yeso hemihidrato $y$ dihidrato en los cementos por análisis térmico
}

\section{INTRODUCCION}

Lehman (1) y Rieke (2) han señalado que la deshidratación térmica del yeso dihidrato es grandemente influenciada por la presión parcial del vapor de agua en la atmósfera que lo rodea, indicando que en presencia de una débil presión de vapor de agua se deshidrata directamente a anhidrita III (soluble).

Este hecho se explica estudiando las tensiones de vapor para cada uno de los hidratos. En el Gmelin-Handbuch der Anorganischen Chemie (3) se indica que en la deshidratación del yeso la formación de anhidrita III (soluble) precede a la formación del hemihidrato $y$, en consecuencia, la presión de disociación del yeso en la formación de anhidrita debe ser mayor que en la formación de hemihidrato. En el Cuadro I se dan las presiones de vapor (tomadas del Gmelin-Handbuch) a varias temperaturas para las diversas transformaciones.

De lo anterior, se deduce que la formación del hemihidrato transcurre según el siguiente mecanismo:

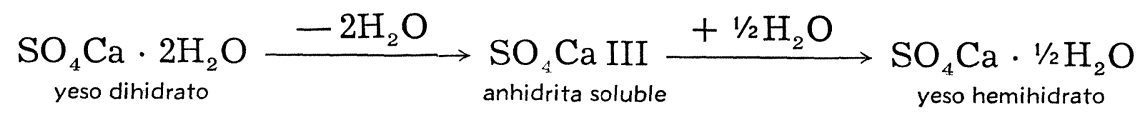

La consecuencia de este comportamiento es la existencia de dos formas de yeso hemihidrato: la $\alpha$ y la $\beta$.

La forma $\alpha$ se obtiene cuando la secuencia de reacciones [I] llega hasta el final. Ello presupone la existencia de cantidad suficiente de agua para hidratar la anhidrita III soluble. El producto obtenido es un producto final de equilibrio. Según el Gmelin-Handbuch (4), la temperatura de transición $\mathrm{SO}_{4} \mathrm{Ca} \cdot 2 \mathrm{H}_{2} \mathrm{O} \stackrel{-2 \mathrm{H}_{2} \mathrm{O}}{\longrightarrow} \mathrm{SO}_{4} \mathrm{Ca}$ III, bajo agua, es aproximadamente de $105^{\circ} \mathrm{C}$ y la correspondiente a la transición $\mathrm{SO}_{4} \mathrm{Ca} \cdot 2 \mathrm{H}_{2} \mathrm{O} \rightarrow \mathrm{SO}_{4} \mathrm{Ca} \cdot 1 / 2 \mathrm{H}_{2} \mathrm{O}$, también bajo agua, es de $126^{\circ}-128^{\circ} \mathrm{C}$. Para poder conseguir esas temperaturas en un ambiente acuoso se emplean disoluciones salinas que elevan la temperatura de ebullición del agua o bien se efectúa la reacción bajo presión de vapor saturado en autoclave $\left(133^{\circ} \mathrm{C}\right)$. 
CUADRO I

Presiones de vapor de los diferentes hidratos del sulfato cálcico

( $\mathrm{mm}$ de $\mathrm{Hg}$ )

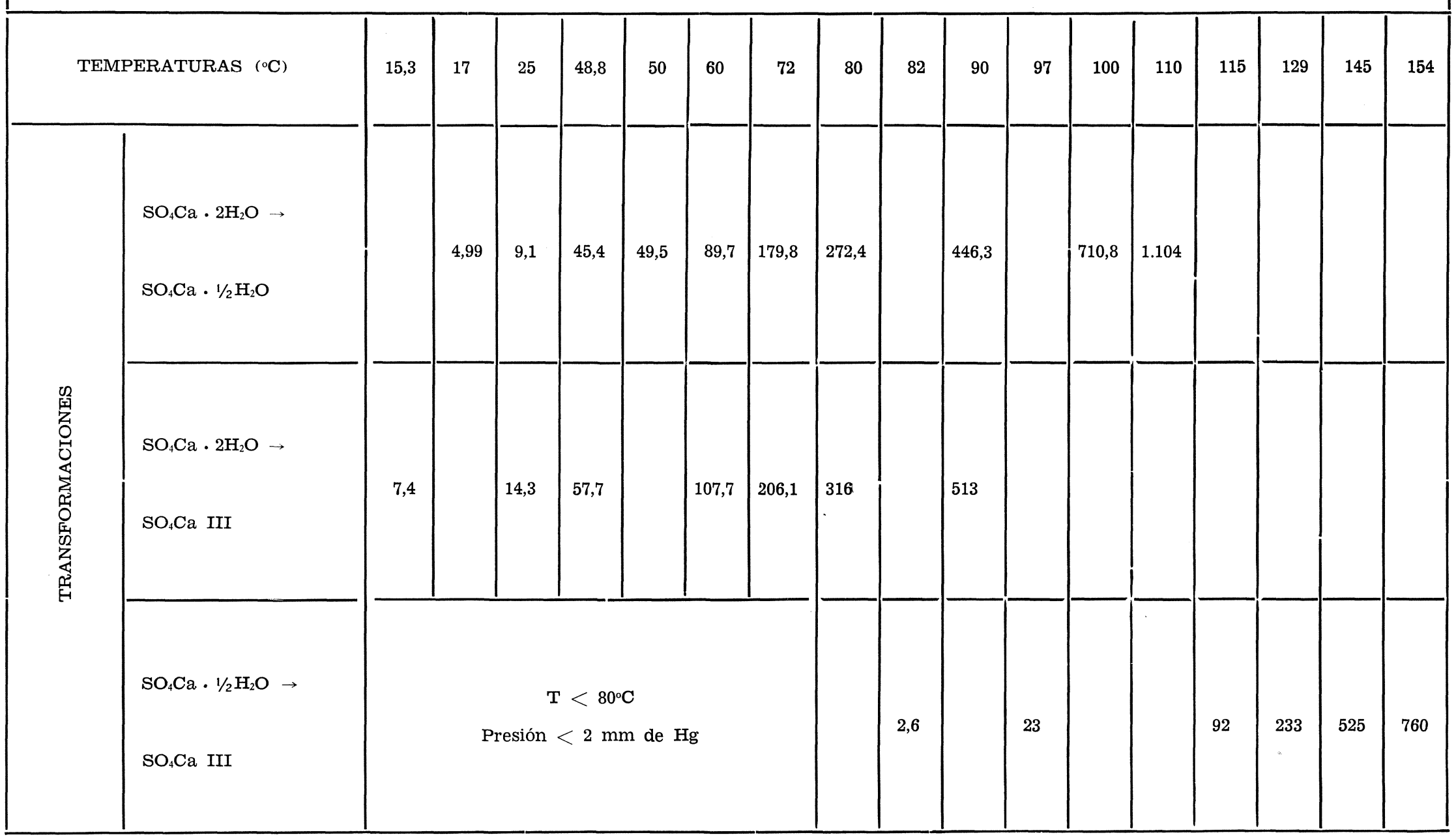


El yeso hemihidrato $\alpha$ se obtiene prácticamente con la composición teórica $1 \mathrm{~mol} \mathrm{SO}_{4} \mathrm{Ca} /$ $/ 0,5 \mathrm{~mol}_{2} \mathrm{O}$. Son cristales mayores y más compactos que los de la forma $\beta$ (5).

La forma $\beta$ resulta al deshidratar el yeso dihidrato calentándolo en aire seco o con baja presión parcial de vapor de agua y durante un tiempo limitado. Sólo se dispone para la rehidratación de la anhidrita III soluble formada en primer lugar, según la reacción [I], del vapor de agua desprendido en la propia deshidratación del yeso, y este agua tiende a escapar. El producto final de equilibrio sería la anhidrita III soluble y el yeso hemihidrato un producto intermedio transitorio. La limitación del tiempo de calentamiento es, pues, importante. El producto final reciente no guardará las proporciones estequiométricas $1 \mathrm{~mol} \mathrm{SO} \mathrm{SO}_{4} \mathrm{Ca} / 0,5 \mathrm{~mol} \mathrm{H}_{2} \mathrm{O}$, pudiendo contener inicialmente un exceso de $\mathrm{SO}_{4} \mathrm{Ca} \cdot 2 \mathrm{H}_{2} \mathrm{O}$ no deshidratado, si el tiempo de calentamiento fue demasiado corto, y probablemente, en cualquier caso, un exceso de $\mathrm{SO}_{4} \mathrm{Ca}$ III. Con el tiempo, y en plazo corto, la anhidrita III soluble se rehidratará con la humedad del aire a $\mathrm{SO}_{4} \mathrm{Ca} \cdot 1 / 2 \mathrm{H}_{2} \mathrm{O}$, ya que según Sato y Kanaya (5) esta rehidratación es casi inmediata. El yeso hemihidrato $\beta$ está constituido por cristales más pequeños porosos y desordenados que los de la forma $\alpha$. Según Bensted y Varna (6), la forma $\beta$, como consecuencia de su estructura porosa, tiene ligeramente más cantidad de agua adsorbida que la $\alpha$ y con agua más móvil que el agua combinada.

Se distinguen las formas $\alpha$ y $\beta$ por análisis térmico diferencial porque la forma $\alpha$ da un pico exotérmico a unos $240^{\circ} \mathrm{C}$ y la $\beta$ a $350^{\circ} \mathrm{C}$, aproximadamente. Estos picos exotérmicos corresponden al derrumbamiento de la estructura del yeso hemihidrato, persistente en la anhidrita III soluble, y formación de la estructura de la anhidrita II insoluble.

\section{ANALISIS TERMICO DEL YESO DIHIDRATO EN ATMOSFERA SECA Y EN ATMOSFERA DE VAPOR DE AGUA}

A continuación se dan una serie de termogramas que muestran gráficamente cuanto se ha dicho en el apartado 1, respecto a la influencia de la presión parcial de vapor de agua en la deshidratación del yeso.

Los análisis térmicos se efectuaron con un termoanalizador, marca Mettler, tipo A-1, n. ${ }^{\circ}$ 57 (fig. 1), que registra simultáneamente y sobre la misma muestra la curva termogravimétrica (TG), derivatométrica (DTG) o de velocidad de pérdida de peso y de análisis térmico diferencial (ATD). Tiene la posibilidad de trabajar con diversas atmósferas en la cámara de reacción, incluido el alto vacío y la atmósfera de vapor de agua. La figura 2 muestra el horno de cuarzo (utilizable hasta $1.000^{\circ} \mathrm{C}$ ) con el dispositivo suministrador de la corriente de vapor de agua. En la figura 3 puede apreciarse el detalle de este dispositivo. La corriente de vapor se insufla en la cámara de reacción haciendo burbujear, a través de agua hirviendo, una corriente de aire descarbonatado. Al interior del horno llegan dos corrientes gaseosas: una, por la parte superior del horno, de vapor saturado y otra, por la parte inferior, de aire seco y descarbonatado. Esta última corriente sirve de protección para el mecanismo de la balanza, impidiendo la penetración de vapor de agua a la misma.

En primer lugar, en la figura 4 se muestra una panorámica de las transformaciones que experimenta el yeso en el curso del calentamiento hasta $1.400^{\circ} \mathrm{C}$. El termograma está realizado en atmósfera de aire seco y a una velocidad de calentamiento relativamente rápida $\left(6^{\circ} \mathrm{C} / \mathrm{min}\right.$.). En consecuencia la deshidratación del yeso transcurre con formación de anhidrita III soluble, parte de la cual se rehidrata a la forma $\beta$ del hemihidrato y que, 
por tener una temperatura de descomposición (a las bajas presiones de vapor existentes) tan baja como la de descomposición del dihidrato, las dos deshidrataciones transcurren simultáneamente y los picos se superponen. Las curvas ATD y DTG sólo presentan una leve inflexión a $170^{\circ}$ que ni se aprecia en las curvas TG.

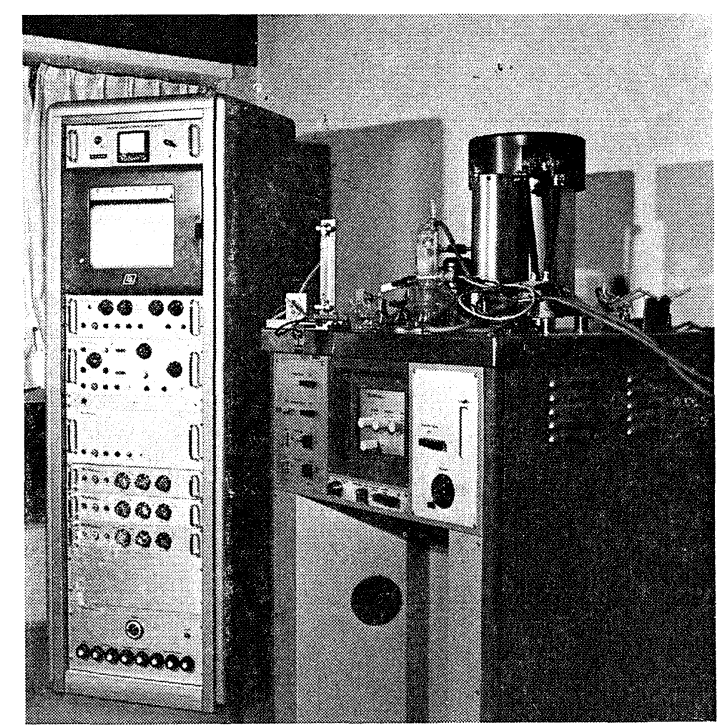

Fig. 1

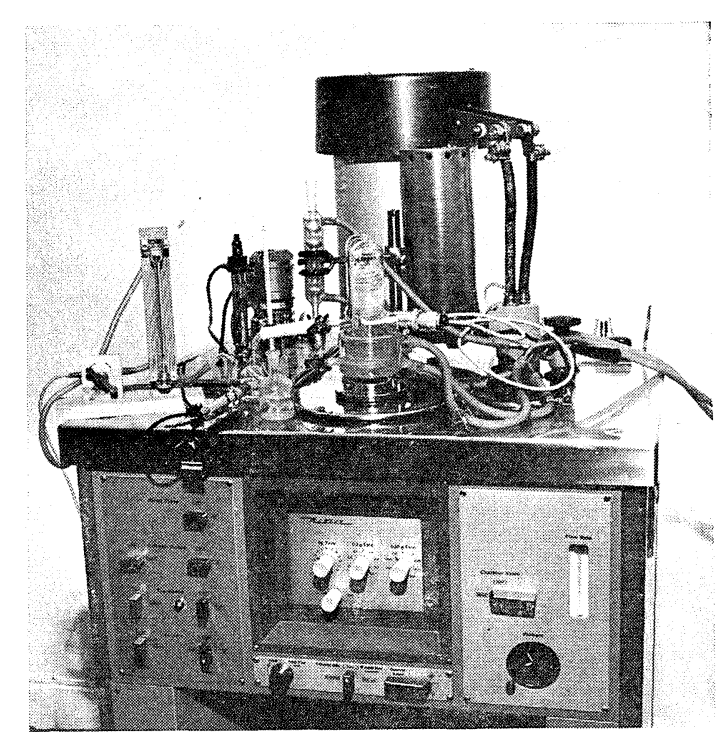

Fig. 2

El yeso hemihidrato que se formó fue el $\beta$ y dio lugar a la $\beta^{-}$anhidrita III soluble. El pico exotérmico de $350^{\circ} \mathrm{C}$ prueba que es la forma $\beta$ y corresponde a la transformación $\beta^{-}$anhidrita III soluble $\rightarrow$ anhidrita II insoluble, ya que la transformación $\alpha$ anhidrita III soluble $\rightarrow$ anhidrita II insoluble transcurre a más baja temperatura $\left(\simeq 240^{\circ} \mathrm{C}\right)$.

Desde $350^{\circ} \mathrm{C}$ hasta $1.210^{\circ} \mathrm{C}$ es estable la anhidrita II insoluble. A $1.210^{\circ} \mathrm{C}$ ocurre la transformación anhidrita II insoluble $\rightarrow$ anhidrita I (calcinada a muerte).

A partir de esta temperatura empieza la descomposición del $\mathrm{SO}_{4} \mathrm{Ca}$ en $\mathrm{SO}_{3}+\mathrm{CaO}$.

Las figuras 5, 6, 7 y 8, 9, 10 muestran la influencia del aumento de la presión parcial del vapor de agua en la curva de descomposición del yeso dihidrato.

Las curvas 5 a 9 han sido efectuadas en idénticas condiciones, variando exclusivamente la presión parcial de vapor de agua en las proximidades de la muestra.

La curva de la figura 5 ha sido realizada en corriente de aire seco y con el crisol que contiene la muestra, destapado. La presión de vapor es mínima, y el paso del dihidrato a anhidrita III soluble transcurre de forma continua sin apenas apreciarse formación de hemihidrato y subsiguiente deshidratación. En la figura 6 puede apreciarse que la colocación de una tapa en el crisol eleva la presión de vapor en el recinto de reacción lo suficiente, como para que la deshidratación del hemihidrato se empiece a diferenciar. Esta diferenciación aumenta, como se ve en la figura 7, al aumentar la presión de vapor en el exterior del crisol (atmósfera de vapor no saturado). 


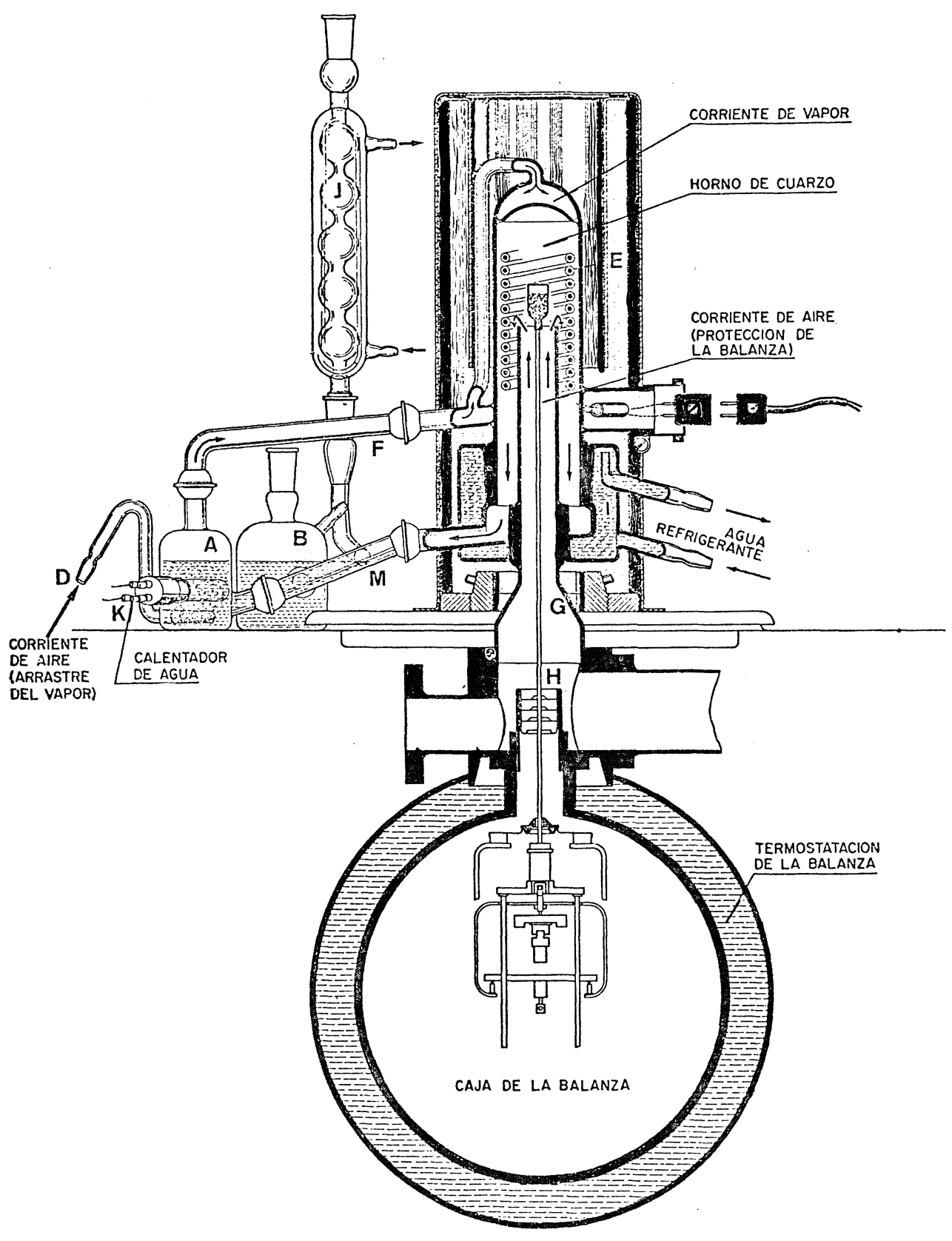

Fig. 3

La diferenciación es máxima y total cuando se rodea el crisol de una atmósfera de vapor saturado (figs. 8, 9 y 10). En este caso la evaluación cuantitativa del yeso dihidrato y hemihidrato es posible con plena garantía.

Las figuras 5 a 8 muestran como la elevación de la presión de vapor eleva también las temperaturas de descomposición de los yesos dihidrato y hemihidrato.

Las figuras 8 y 9 corresponden a la deshidratación del yeso dihidrato Merck (reactivo para análisis). La diferencia entre el termograma 8 y el 9 es que, en el caso de la figura 9, la muestra se secó por tratamiento con acetona, éter y posterior vacío. En ambos casos 
se calculó el porcentaje de pureza, resultando ser del 89,11 o del $86,93 \%$ según se calcule a partir de la figura 8 o de la 9 respectivamente. Puede apreciarse que un error en la lectura del diagrama de $\pm 0,05 \mathrm{mg}$ (media división pequeña) conduce a un error de $\pm 2 \%$ en el $\%$ de pureza.
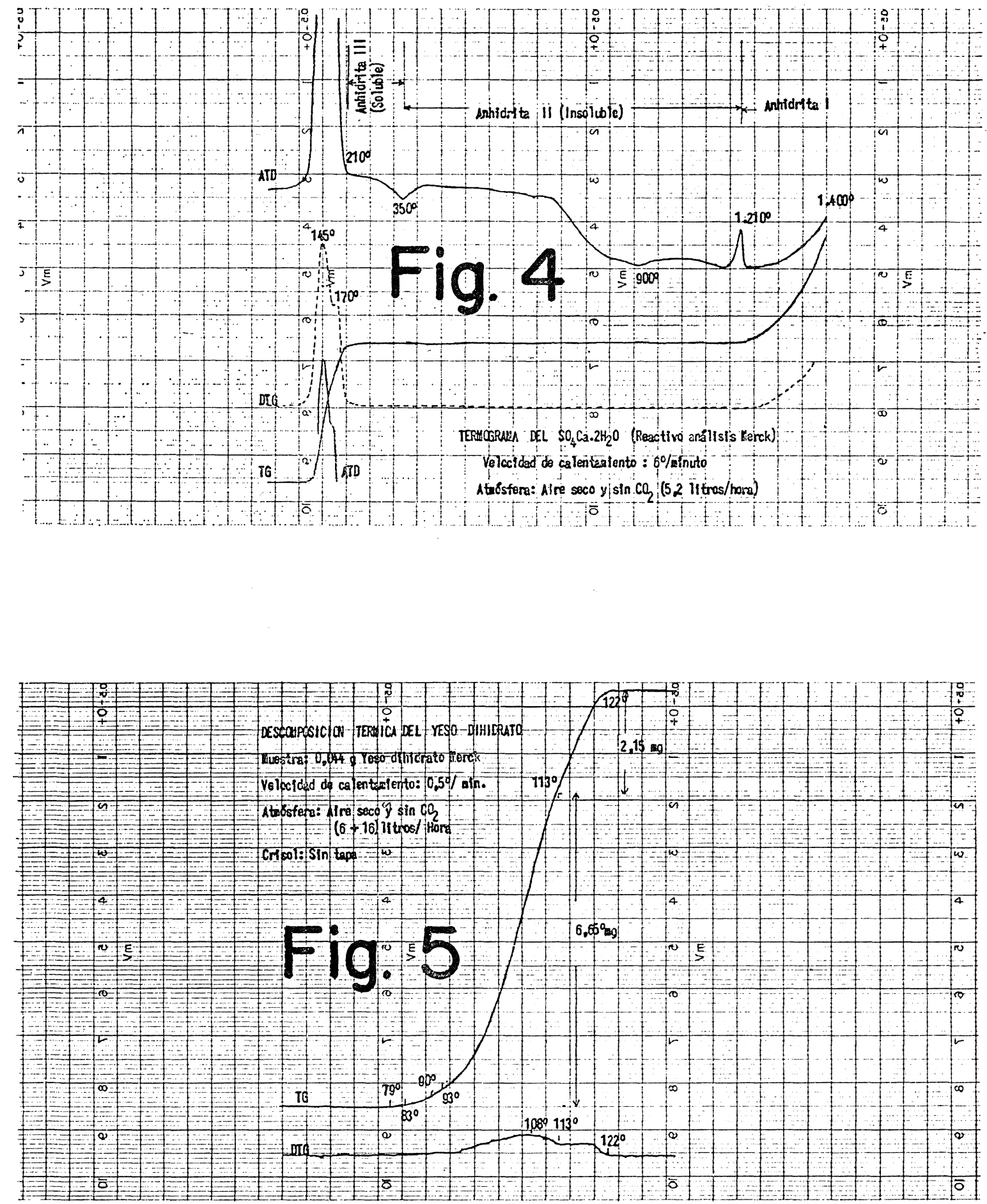

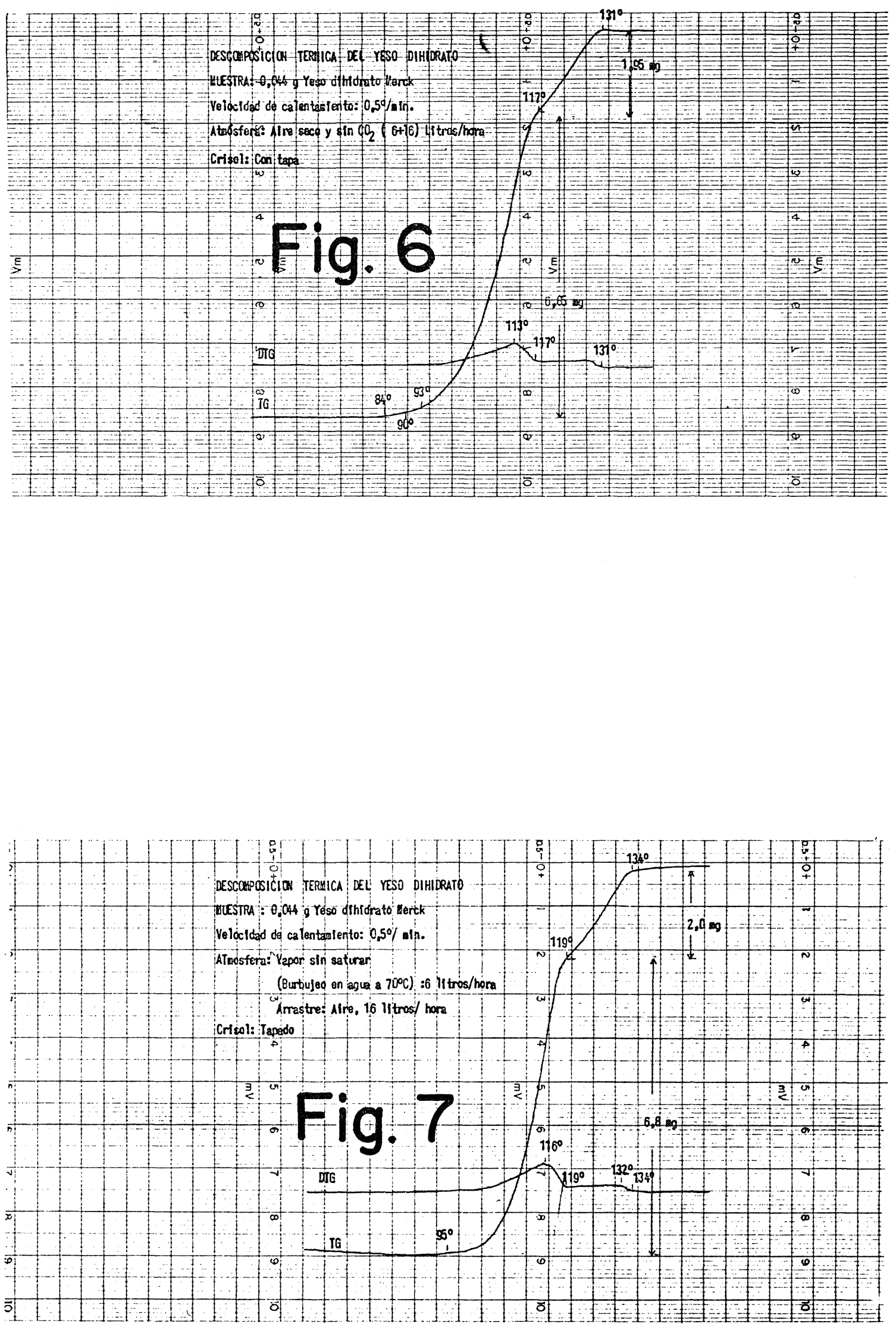

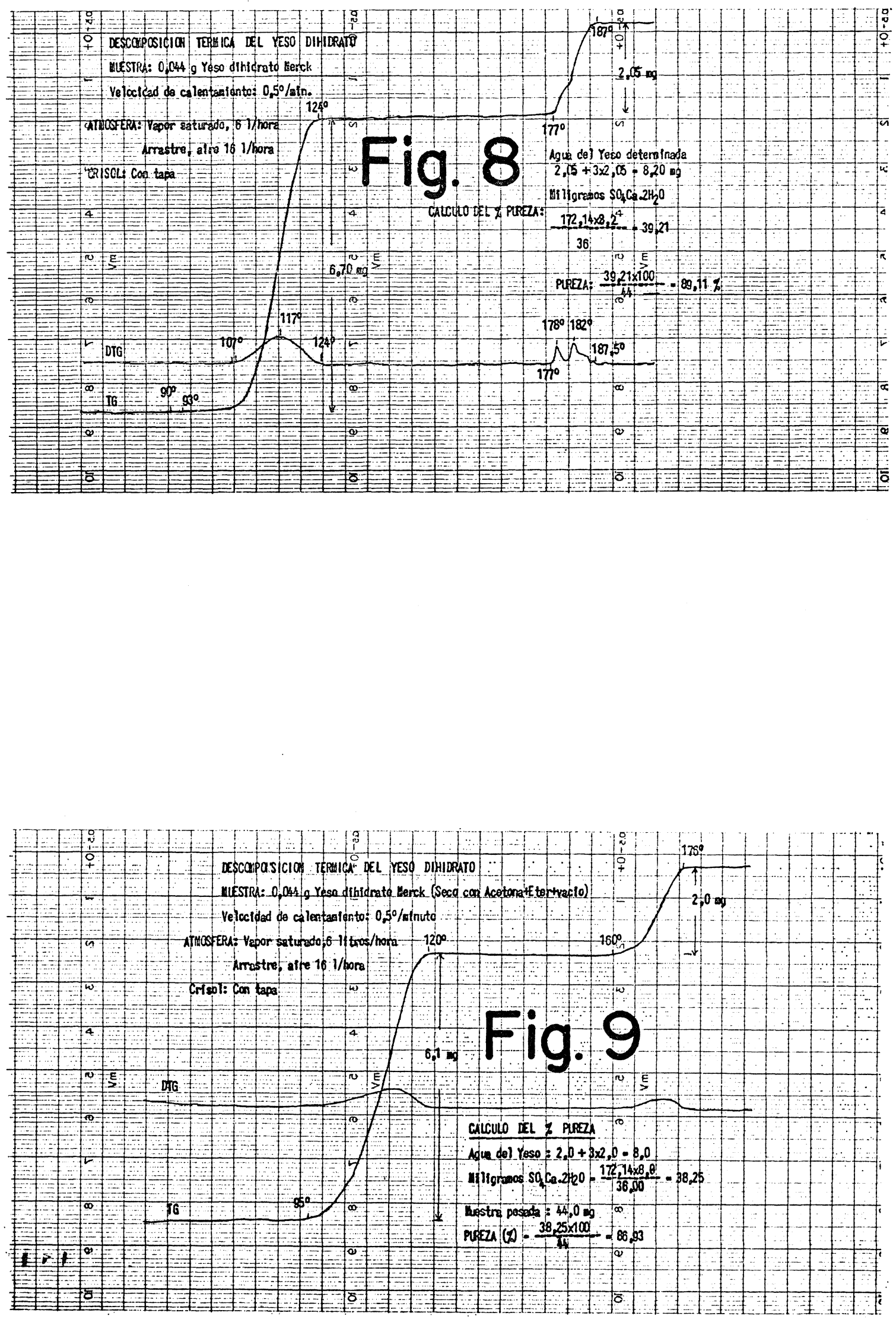
La figura 10 indica el termograma de una piedra de yeso realizado en iguales condiciones que los 5 y 6 (excepto velocidad del calentamiento que fue de $1^{\circ} \mathrm{C} / \mathrm{min}$ ). El porcentaje de pureza calculado resultó ser también de 86,93\% (como el dihidrato Merck).

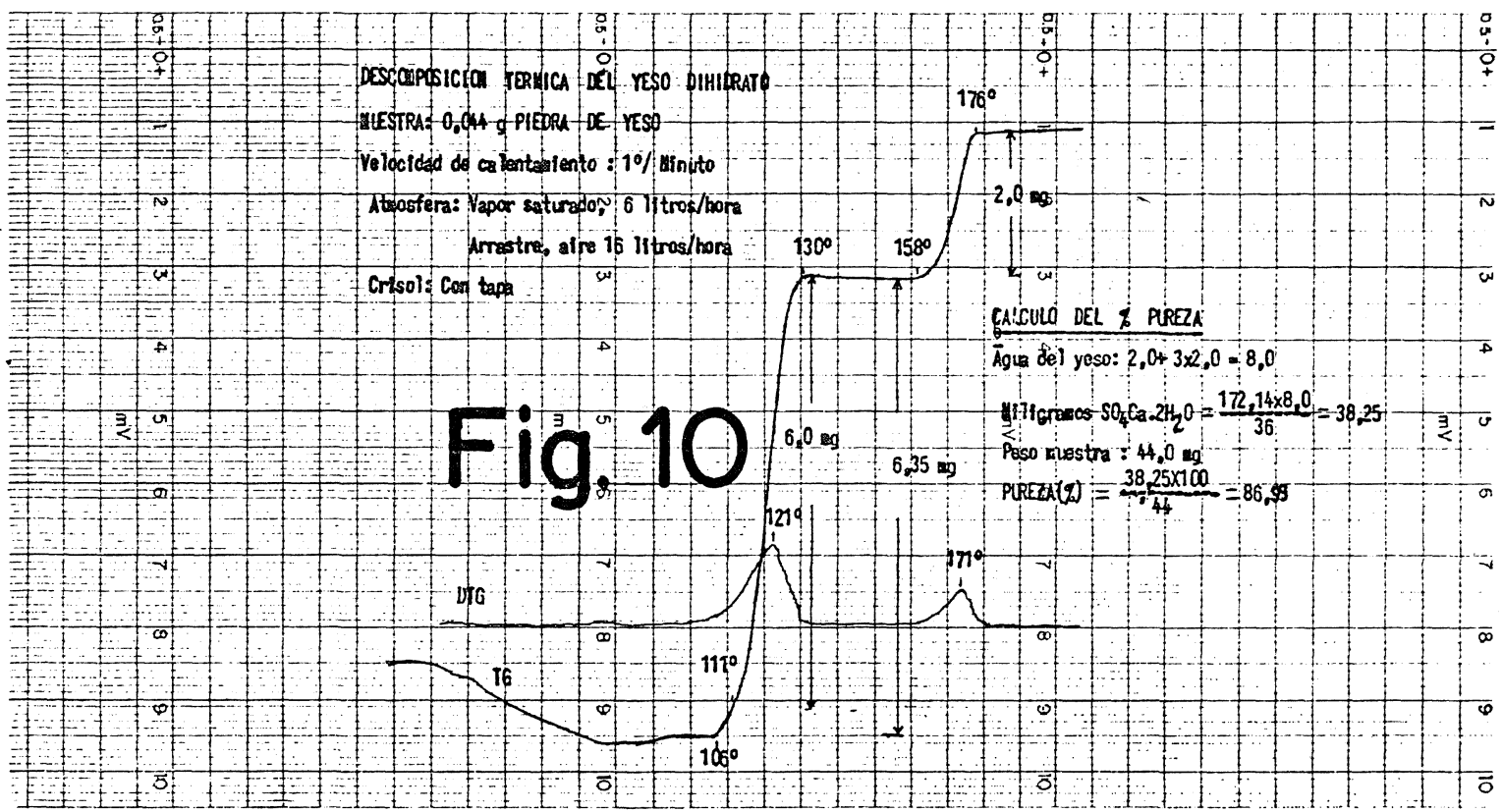

La figura 11 muestra las curvas termogravimétricas, ATD y DTG, calentamiento y enfriamiento, del yeso dihidrato Merck (R. A.), en atmósfera saturada de vapor de agua. En el calentamiento se llegó hasta la temperatura de $180^{\circ} \mathrm{C}$, es decir, se llegó a completar la deshidratación del yeso hemihidrato y a formar la anhidrita III soluble. El enfriamiento muestra la rehidratación cuantitativa de la anhidrita III soluble a yeso hemihidrato, mediante la atmósfera de vapor de agua. Esta rehidratación transcurre con un cierto retraso con respecto a las temperaturas de deshidratación correspondientes. De la curva de enfriamiento se deduce también que la hidratación del hemihidrato a dihidrato no ocurre con vapor de agua a la presión ordinaria, es necesario, para ello, la condensación de agua líquida sobre la muestra. La cantidad de agua condensada no corresponde a la cantidad de agua perdida al pasar de dihidrato a hemihidrato, sino que es mayor que ésta.

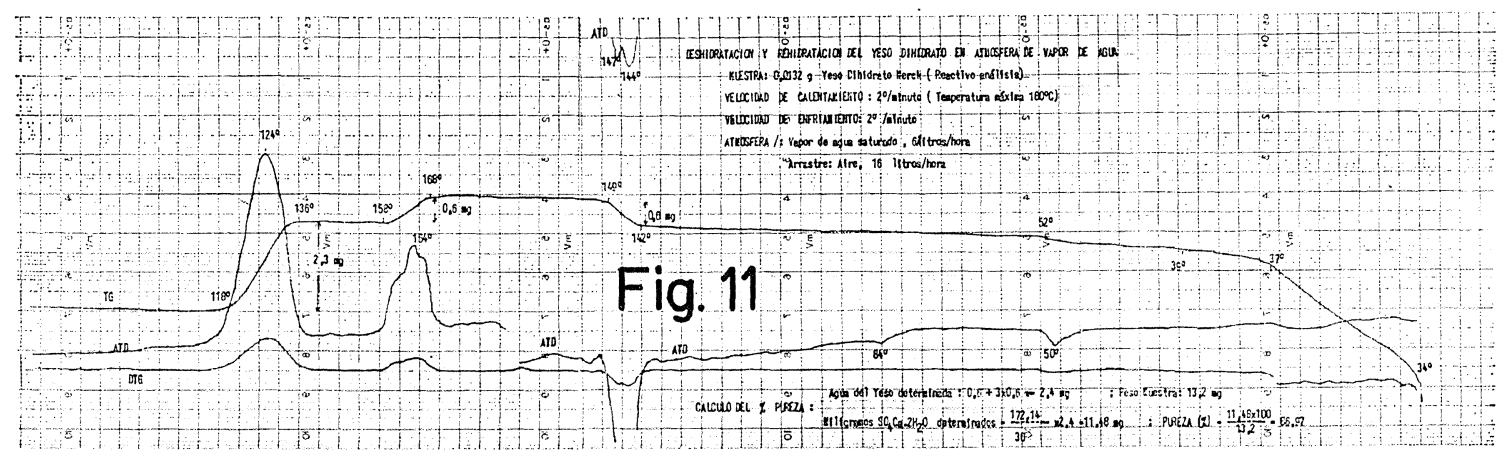


El porcentaje de pureza para el yeso dihidrato Merck (R. A.) calculado con este termoanálisis (fig. 11) es del 86,97 \% y coincide prácticamente con el obtenido a partir del termograma de la figura 9. Para los cálculos que posteriormente se harán se tomará como porcentaje de pureza el valor medio de los obtenidos con los termogramas 9 y 11, pureza $(\%)=86,95$.

\section{LA DETERMINACION DEL CONTENIDO DE YESO DIHIDRATO Y HEMIHIDRATO EN LOS CEMENTOS POR ANALISIS TERMICO}

La determinación del contenido de yeso dihidrato y hemihidrato en los cementos se ha abordado por dos técnicas de análisis térmico: análisis térmico diferencial (ATD) y análisis termogravimétrico (TG).

El principio en que se basan ambos métodos es el mismo, la deshidratación al menos aparente, del yeso dihidrato en dos etapas:

1. ${ }^{a}$ etapa: Pérdida de $1 \frac{1}{2}$ molécula de agua y conversión en hemihidrato.

2. ${ }^{a}$ etapa: Pérdida de $1 / 2$ molécula de agua y conversión en anhidrita III (soluble).

El método TG se limita a medir directamente en el termograma la pérdida de peso experimentada en cada etapa, y de ella deduce, también directamente, el contenido de cada clase de yeso. El método ATD, que mide la cantidad de calor absorbida por cada etapa de deshidratación, requiere las calibraciones correspondientes para llegar al resultado cuantitativo.

Si las condiciones de deshidratación (presión parcial de vapor de agua y velocidad de calentamiento) son tales que las dos etapas no están perfectamente separadas, no podrá llevarse a cabo la determinación en forma adecuada por ninguna de las dos técnicas ATD o TG.

Es curioso señalar que, a pesar de la mayor simplicidad y menor posibilidad de error del método TG, se haya desarrollado más tardíamente que el método ATD. Posiblemente esto deba ser relacionado con el desarrollo de las termobalanzas, capaces de operar en atmósferas de vapor de agua y quizas también con un mayor aislamiento de la muestra, con respecto a la atmósfera, en los aparatos de análisis térmico diferencial, lo que puede permitir desarrollar en los pocillos para la muestra una presión parcial de vapor de agua suficiente como para evitar la superposición parcial de ambas etapas de deshidratación. En nuestros ensayos no hemos podido, sin embargo, evitar esa parcial superposición con el solo hecho de poner una tapa al recinto de la reacción. Otra razón para el más temprano desarrollo del método ATD puede haber sido la siguiente: el que así como en termogravimetría se puede fácilmente controlar y comprobar si en unas condiciones experimentales dadas hay superposición parcial de etapas de deshidratación, en el ATD esta comprobación no es tan evidente. Los buenos resultados apuntados para el método ATD por la bibliografía (5) y (7) pueden deberse a una compensación de errores en las diversas etapas de calibrado.

\subsection{El método ATD}

En 1962, Sato y Kanaya (5) publicaron un trabajo en el que mostraban cómo podía determinarse cuantitativamente el contenido de yeso dihidrato y hemihidrato en el cemento portland por análisis térmico diferencial. 
Determinan el porcentaje de $\mathrm{SO}_{3}$ en el cemento, en cada una de las formas, dihidrato y hemihidrato. Para ello utilizan 2 curvas de calibrado confeccionadas por adición de clínkeres de mezclas de yeso dihidrato y hemihidrato. Una de las curvas da, a partir de la relación de áreas $a_{1}$ y $a_{2}$ del $1 .{ }^{\mathrm{er}}$ al $2 .^{\circ}$ pico, respectivamente, las contribuciones relativas [A] $(0$ al $100 \%)$ y [B] $(100$ al $0 \%)([\mathrm{A}]+[\mathrm{B}]=100)$ al contenido de $\mathrm{SO}_{3}$ por el dihidrato y por el hemihidrato. A partir de estos valores [A] y [B], mediante las fórmulas

$$
a_{\mathrm{A}}=\frac{4[\mathrm{~A}]}{4[\mathrm{~A}]+[\mathrm{B}]} \times a_{\mathrm{T}} \quad ; \quad a_{\mathrm{B}}=\frac{[\mathrm{B}]}{4[\mathrm{~A}]+[\mathrm{B}]} \times a_{\mathrm{T}}
$$

calculan las áreas $a_{\mathrm{A}} \mathrm{y} a_{\mathrm{B}}$, siendo $a_{\mathrm{A}}$ la suma de las áreas de los 2 picos producidos por el dihidrato у $a_{\mathrm{B}}$ la parte de área del $2 .^{\circ}$ pico producida por el hemihidrato, de forma que $a_{1}+a_{2}=a_{\mathrm{A}}+a_{\mathrm{B}}=a_{\mathrm{T}}$. Con los valores de $a_{\mathrm{A}} \mathrm{y} a_{\mathrm{B}}$, mediante la 2. ${ }^{\mathrm{a}}$ curva de calibrado, determinan, finalmente, los porcentajes de $\mathrm{SO}_{3}$ como dihidrato $\mathrm{S}_{\mathrm{A}}$ y como hemihidrato $\mathrm{S}_{\mathrm{B}}$.

A St. John (7) estudiando el trabajo de Sato y Kanaya, con la aportación de experiencias propias, llega a la conclusión de que el método desarrollado por estos investigadores no puede ser aplicado a los cementos, ya que el yeso dihidrato/hemihidrato no está presente en los cementos como una simple mezcla, sino como un yeso parcialmente deshidratado el cual da curvas de calibración que difieren considerablemente de las obtenidas adicionando mezclas dihidrato/hemihidrato al cemento. En consecuencia St. John, lo que hace es obtener curvas de calibrado confeccionadas mezclando yeso dihidrato, parcialmente deshidratado, a los clínkeres. Efectuar la deshidratación parcial del yeso, calentándolo a $90^{\circ}-95^{\circ} \mathrm{C}$ durante tiempos diferentes. Inmediatamente antes de mezclar el yeso parcialmente deshidratado con el clínker, determina su pérdida al fuego $P_{2}(\%)$ a $215^{\circ}-$ $230^{\circ} \mathrm{C}$ con lo que, por diferencia con su pérdida al fuego original $P_{1}(\%)$ a la misma temperatura, calculan el porcentaje de yeso hemihidrato $=\frac{\left(P_{1}-P_{2}\right) 145,14}{3 \times 9}$. La diferencia a 100 constituye el yeso dihidrato remanente.

Sato y Kanaya señalan para la reproductibilidad del método una desviación estándar de $0,03 \%$ para cada forma de sulfato cálcico.

\subsection{El método termogravimétrico}

\subsubsection{Referencias bibliográficas}

Se han señalado dos métodos para determinar los porcentajes de yeso dihidrato en una mezcla. Keatch (8) emplea la termogravimetría isoterma y halla la proporción entre yeso dihidrato y hemihidrato en los yesos comerciales y materias primas yesíferas, manteniendo la muestra a $90^{\circ}-93^{\circ} \mathrm{C}$ unas 2 horas para deshidratar $1 \frac{1}{2}$ moléculas de agua. La $1 / 2$ molécula de agua restante la determina calentando a $160^{\circ} \mathrm{C}$.

Bernard (9), por su parte estudia el problema de la determinación de las proporciones de yeso dihidrato y hemihidrato en el cemento por termogravimetría dinámica en corriente de vapor de agua y con un programa de elevación de temperatura de $0,83^{\circ} \mathrm{C} / \mathrm{min}$ $\left(50^{\circ} \mathrm{C} /\right.$ hora $)$. En su trabajo, Bernard ensaya mezclas sintéticas de yeso dihidrato-hemihidrato y determina sus proporciones mediante esta técnica señalando errores relativos que varían para el dihidrato del 0 al $-0,12 \%$ (3 ensayos) y para el hemihidrato del 
- 4 al + $6 \%$. También efectúa mezclas sintéticas de clínker y yeso dihidrato hallando termogravimétricamente la proporción de dihidrato en el clínker con errores relativos del -2 al $-4 \%$ (mezclas con 5 y $10 \%$ de yeso dihidrato).

\subsubsection{Parte experimental}

\subsubsection{Deshidratación isotérmica del yeso}

En primer lugar se ha tratado de comprobar el método de Keatch (8), según el cual se podía determinar los porcentajes de yeso dihidrato y hemihidrato, en una mezcla de ambos, mediante calentamiento isotérmico durante 2 horas a una temperatura entre $90^{\circ}$ y $93^{\circ} \mathrm{C}$ para el paso de dihidrato a hemihidrato, seguido de otro calentamiento isotérmico a $160^{\circ} \mathrm{C}$ para el paso de hemihidrato a anhidrita soluble.

En las figuras 5 y 6 , termogramas realizados en ambiente seco, se señalaron sobre las curvas TG las temperaturas de $90^{\circ}$ y $93^{\circ} \mathrm{C}$. Puede apreciarse que a esas temperaturas ya empieza la curva TG a elevar su pendiente de deshidratación.

Las figuras 8, 9 y 10 muestran, por otra parte, que en ambiente saturado de humedad no empieza a elevarse la pendiente de deshidratación hasta los $100^{\circ}-105^{\circ} \mathrm{C}$.

En consecuencia, se ha tratado de comprobar el método de Keatch en ambiente seco. La figura 12 muestra que un calentamiento isotérmico a $91^{\circ} \mathrm{C}$ hasta llegar al equilibrio, conduce a la deshidratación total del yeso dihidrato para formar anhidrita III soluble. En las condiciones de nuestro ensayo esto ocurre después de un calentamiento isotérmico de 7 horas. La figura 12 muestra también que con un calentamiento de 2 horas (siempre en las condiciones de nuestro ensayo) no se llega a la obtención de yeso $\beta$-hemihidrato puro, sino a una mezcla dihidrato-hemihidrato o "yeso parcialmente deshidratado" [según St. John (7)]. La figura 13 representa el termograma de deshidratación isotérmica a $98^{\circ} \mathrm{C}$ del yeso dihidrato. A esta temperatura la deshidratación total y paso a anhidrita III soluble, ya ha ocurrido al cabo de 2 horas.

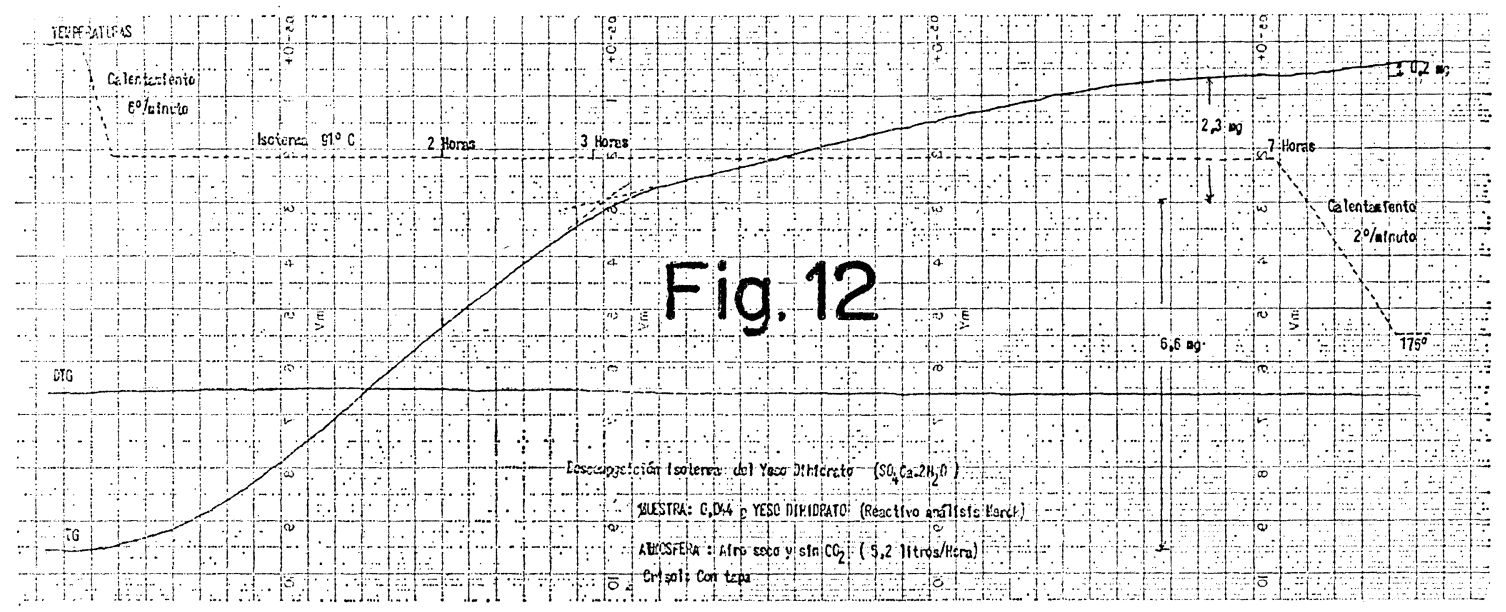




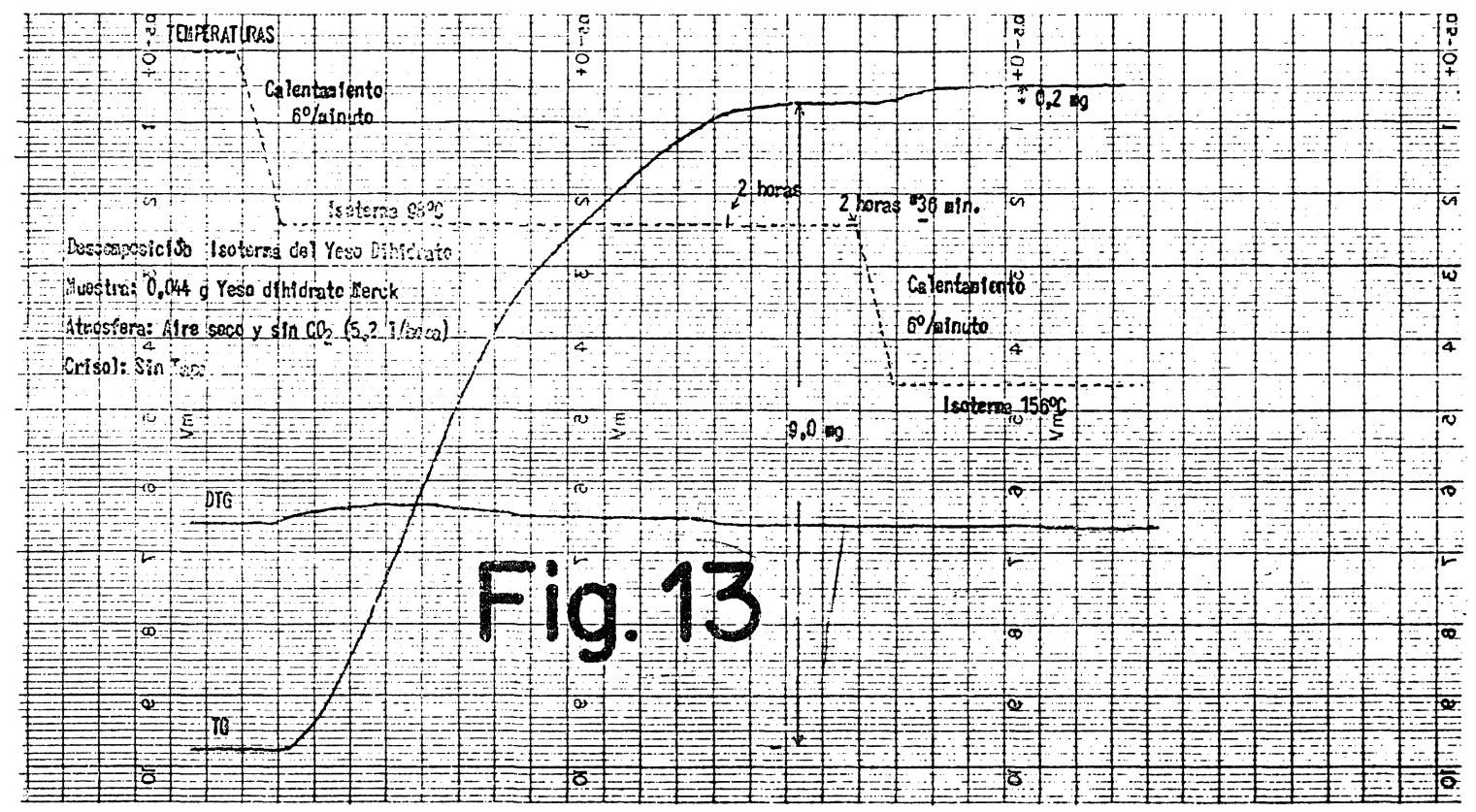

Tanto en la figura 12 como en la 13 pueden verse también que es posible obtener yeso hemihidrato $\beta$ por deshidratación isotérmica en aire seco, pero graduando el tiempo de calentamiento en función de las condiciones específicas de temperatura, cantidad de muestra, y facilidad de escape del agua procedente de la deshidratación. La dependencia del resultado, de variables específicas de cada material y de las condiciones locales del dispositivo de calentamiento, hacen que éste no pueda ser un método general para el análisis de las proporciones de dihidrato y hemihidrato en una mezcla, aunque sí pueda serlo, y de hecho lo sea, un método de fabricación de yeso $\beta$-hemihidrato.

\subsubsection{Mezclas yeso dihidrato-diluyente (inerte y activo)}

En segundo lugar se mostraron los resultados obtenidos, mediante la Termogravimetría en atmósfera de vapor de agua, en la determinación del contenido de pequeños porcentajes de yeso dihidrato, añadidos a diversos materiales inertes o activos frente al yeso $\mathrm{y}$, especialmente, inertes o activos frente al vapor de agua.

Para estudiar el comportamiento, de diversos materiales empleados como diluyentes, frente al vapor de agua, se han realizado sus termogramas sin adición alguna. Se emplearon idénticas cantidades de muestra, gastos de vapor de agua y de aire, y velocidades de calentamiento que más tarde se emplearon en las mezclas con yeso. La figura 14 muestra estos termogramas: la curva 1 es la curva termogravimétrica del crisol de platino empleado, vacío; la curva 2, es un clínker molido a finura menor de 200 micras, cuyo análisis químico se da en el cuadro II ; la curva 3 es la del óxido de aluminio $\left(\mathrm{Al}_{2} \mathrm{O}_{3}\right)$ Probus, Calidad Q.P.; finalmente la curva 4 , corresponde a cuarzo (arena de Otawa) molido a la misma finura que el clínker.

Puede observarse que el cuarzo molido es el único material prácticamente inerte frente al vapor de agua hasta $189^{\circ} \mathrm{C}$. 
En consecuencia, en sus mezclas con yeso, la determinación termogravimétrica del porcentaje de éste último ofrece los mejores resultados. La figura 15 muestra el termograma del cuarzo molido conteniendo 4,76 \% de yeso dihidrato Merck (de 86,95 \% de pureza). Los miligramos añadidos de $\mathrm{SO}_{4} \mathrm{Ca} \cdot 2 \mathrm{H}_{2} \mathrm{O}$ puro a $600 \mathrm{mg}$ de cuarzo molido fueron 26,08, y los encontrados, $25,82 \mathrm{mg}$, lo que representa un error relativo $E_{\mathrm{r}}=-0,99$ $\%$ (el $1 \%$ por defecto).

La alúmina es activa frente al vapor de agua. Su gran superficie activa (empleo en cromatografía) hace que se adsorban moléculas de agua, procedentes del vapor. Su curva termogravimétrica (curva 3 de la figura 14 ) muestra que a $85^{\circ} \mathrm{C}$ hay un aumento de peso por adsorción de agua y a partir de $95-100^{\circ} \mathrm{C}$ empieza una disminución continua de peso por desorción gradual del agua adsorbida. La figura 16 corresponde a la curva termogravimétrica de $880 \mathrm{mg}$ de una mezcla de alúmina con yeso dihidrato Merck (en la proporción de 4,76\%). Pueden observarse, bien diferenciados, los 2 escalones de deshidratación del yeso, pero existe una superposicón de salida de agua correspondiente a la adsorbida por la alúmina. Esta superposición de salidas de distintas clases de agua conduce a peores resultados en la determinación del contenido de yeso dihidrato que en el caso de salida exclusiva del agua correspondiente al yeso (caso del cuarzo como material inerte). En efecto, sin efectuar correcciones, el porcentaje de yeso dihidrato se determinó en este caso con un error relativo de $+7,66 \%$, mientras que corrigiendo por la salida de agua de adsorción el error fue de $-8,1 \%$. La corrección se efectuó calculando la pérdida de peso por unidad de tiempo en el tramo de curva comprendido entre las dos etapas de deshidratación de yeso.

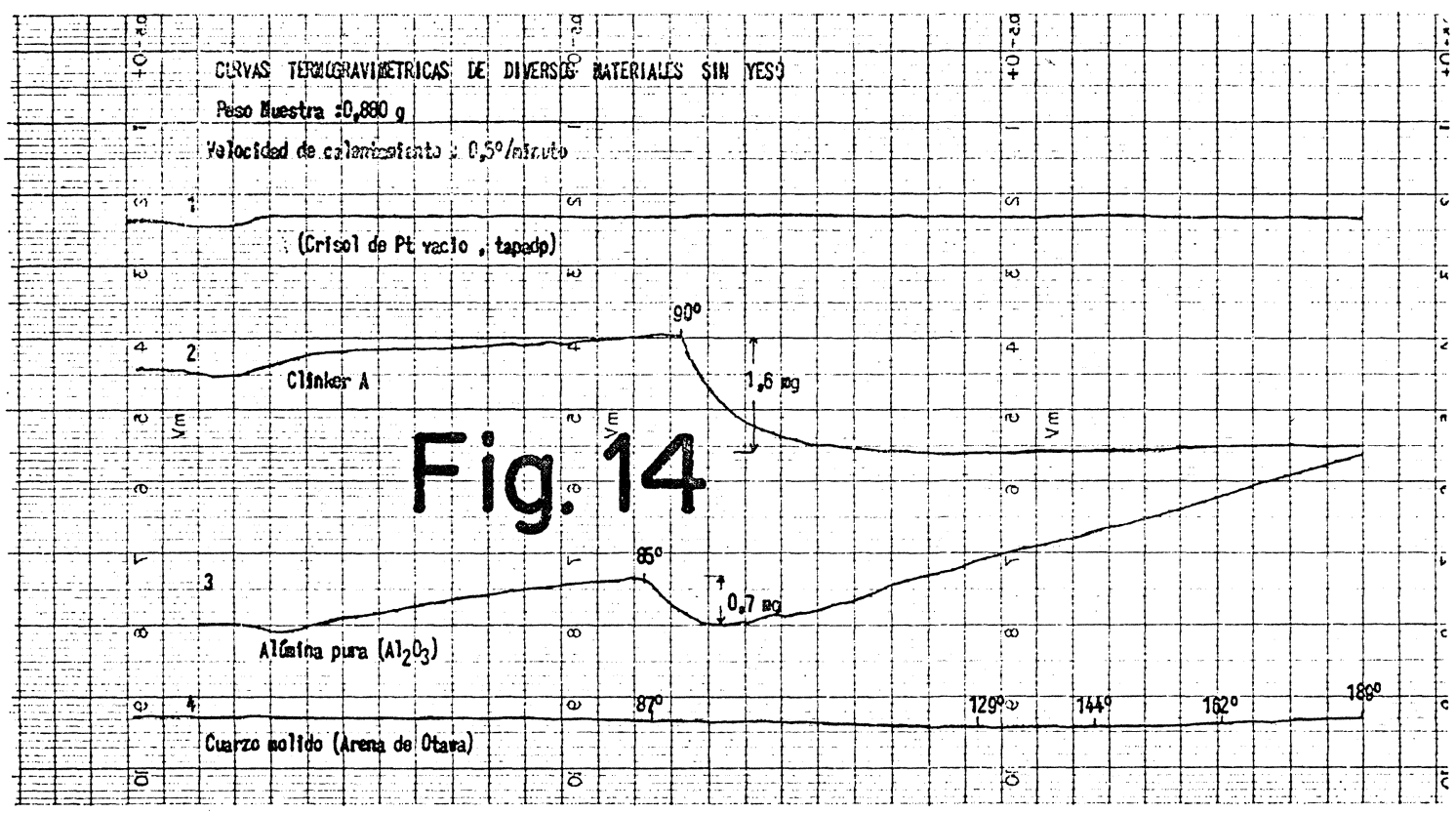

Finalmente, el clínker A (curva 2 de la figura 14) muestra un aumento de peso entre $90^{\circ}$ y $105^{\circ} \mathrm{C}$, tras lo cual el peso permanece constante (hasta $189^{\circ} \mathrm{C}$, límite estudiado). Este aumento de peso puede adscribirse a la hidratación de la cal libre, o al menos parte de ella, por el vapor de agua (el análisis del clínker, dado en el cuadro II, muestra que este 
clínker tiene un fuerte contenido de cal libre). Se utilizó este clínker con alto contenido de cal libre, porque precisamente ello le hace presentar una particularidad que es necesario tener muy en cuenta al determinar el contenido de yeso en sus mezclas con él. Esta particularidad se refiere a la temperatura que debe tener la muestra cuando el vapor saturado alcance sus proximidades.
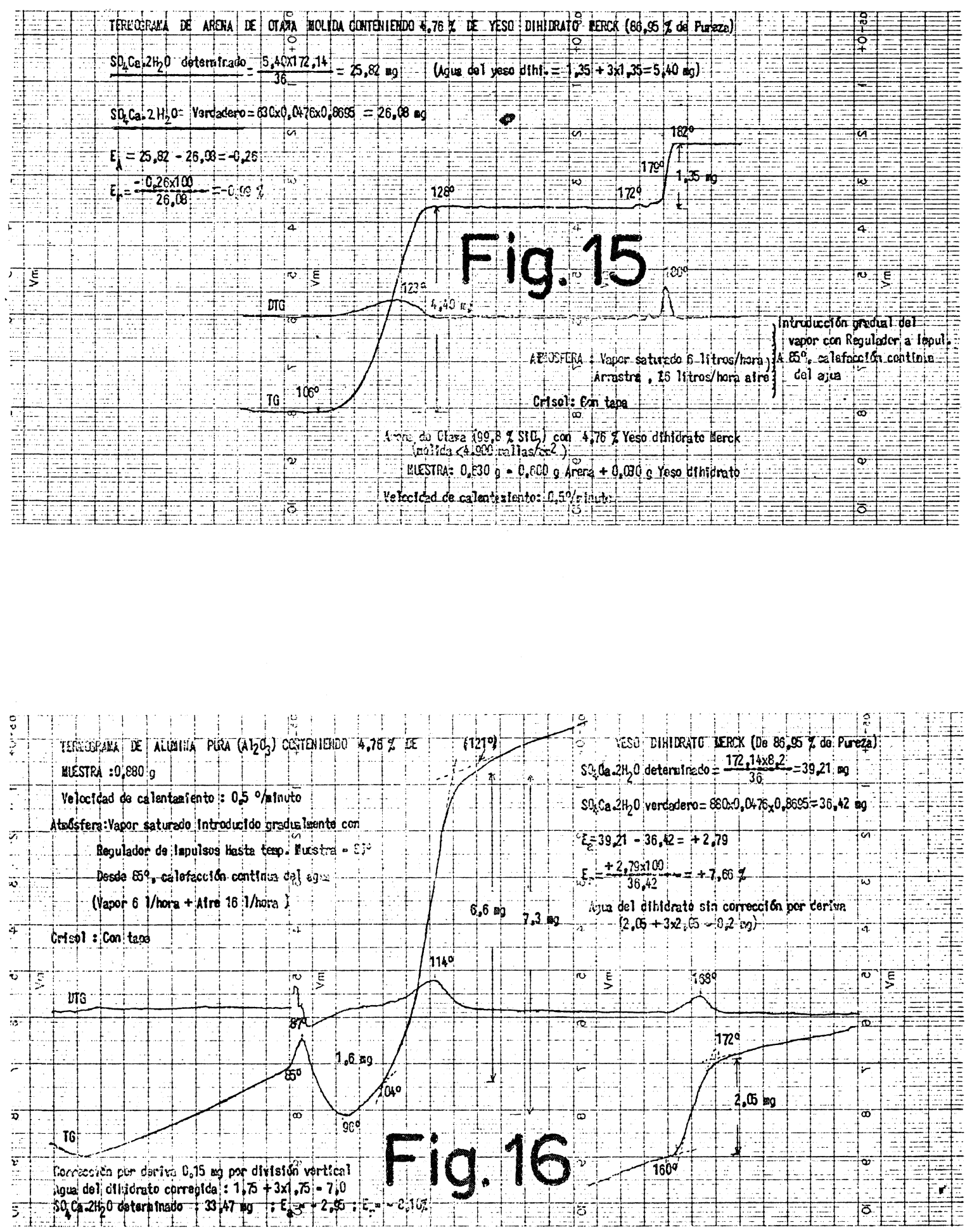
En las figuras 17 y 18 puede verse el termograma de $880 \mathrm{mg}$ de una mezcla de yeso dihidrato Merck y clínker A, en la proporción de 4,76 \% del primero. La única diferencia entre uno y otro termograma consiste en la temperatura de la muestra cuando el vapor saturado alcanza sus proximidades.
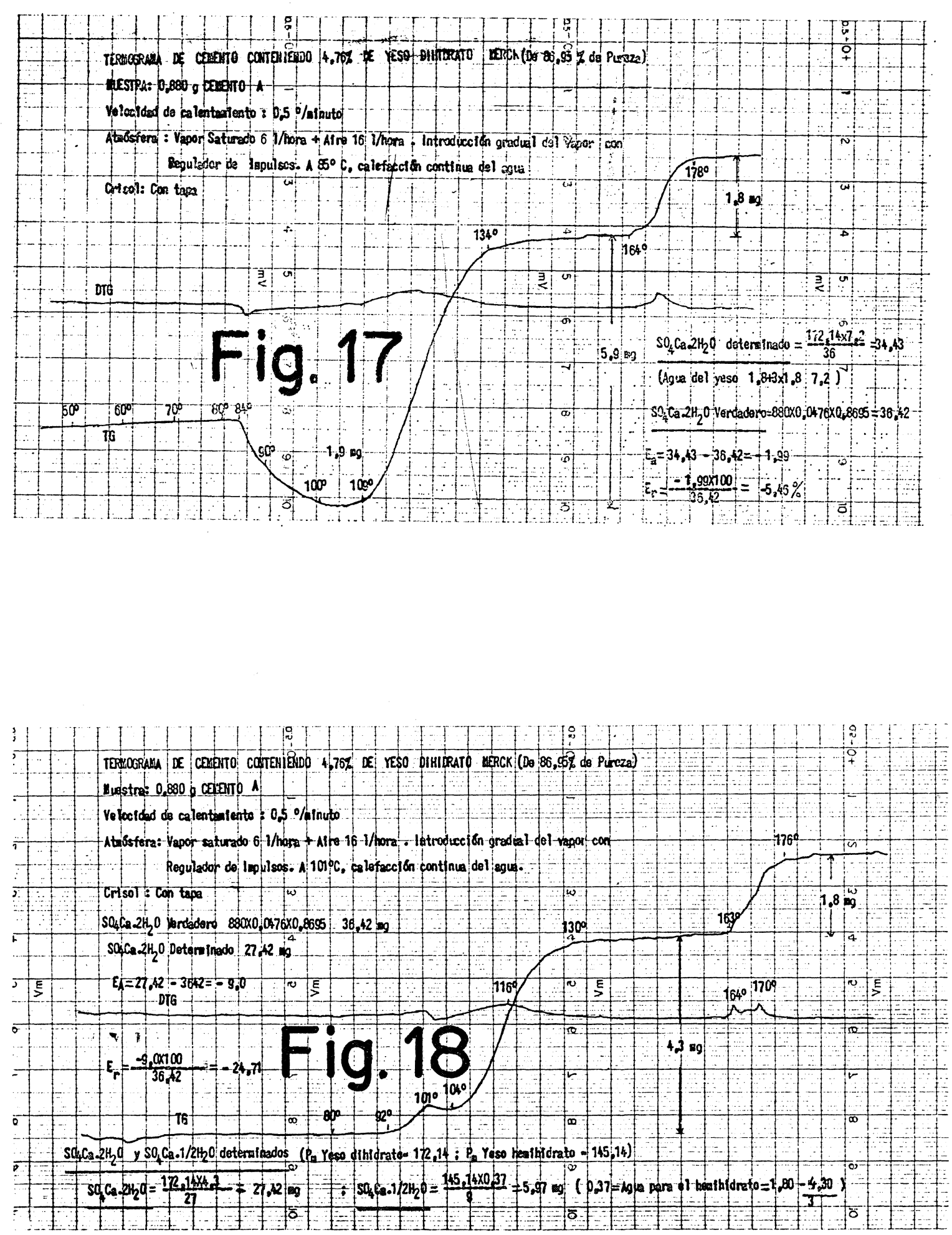
Para que no existan condensaciones de agua sobre la muestra o sobre el crisol, lo que estropearía el termograma, la llegada de vapor a la termobalanza ha de ser paulatina e ir de acuerdo con la temperatura alcanzada por la muestra o crisol. Esto se realiza calentando el recipiente de agua generador del vapor, también paulatinamente, de forma que la temperatura del agua, a través de la cual burbujea la corriente de aire de arrastre, vaya subiendo en función de la temperatura de la muestra y alcance la temperatura de ebullición cuando la muestra llegue a una temperatura dada, que se determina experimentalmente mediante tanteos. El calentamiento paulatino del agua se efectuó intercalando un regulador de impulsos (Prolabo), en el circuito de calefacción y elevando un punto el mando del regulador al alcanzar, el registrador digital del programa de calentamiento, las temperaturas que se expresan en el cuadro III.

El termograma de la figura 16, y todos los efectuados en atmósfera de vapor de agua con excepción del termograma de la figura 18, se realizó según las indicaciones del cuadro III. El termograma de la figura 18 se efectuó manteniendo el regulador de impulsos en el punto 5 hasta los $100^{\circ} \mathrm{C}$, momento en que se realizó la desconexión del regulador y el enchufe directo y continuo a la red del sistema de calefacción del agua.

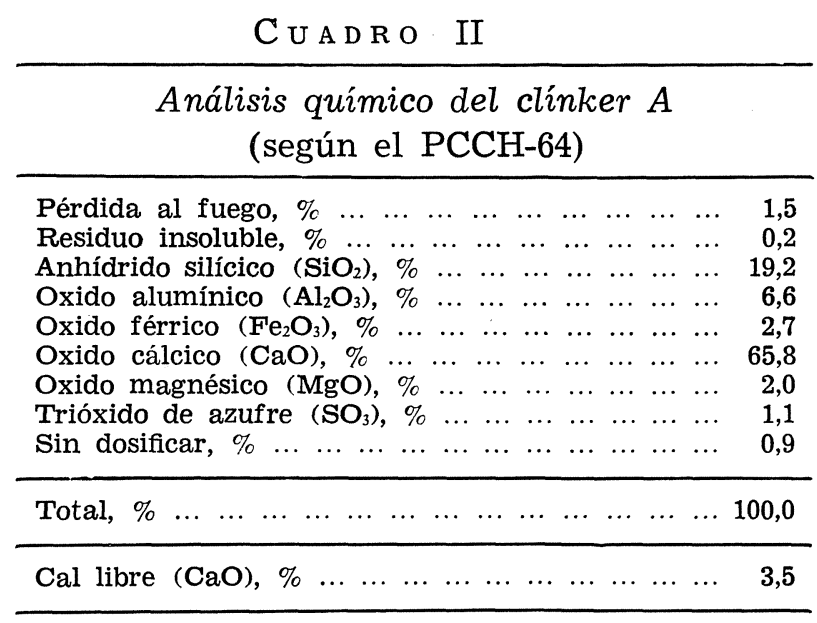

C U A D R O III

\begin{tabular}{cc}
\hline $\begin{array}{c}\text { Temperatura del registrador } \\
\text { digital del programa }\left({ }^{\circ} \mathbf{C}\right)\end{array}$ & $\begin{array}{c}\text { Posición del mando del Regulador } \\
\text { a impulsos (Prolabo) }\end{array}$ \\
\hline 50 & 2 \\
60 & 3 \\
70 & 4 \\
80 & 5 \\
85 & Calefacción continua y directa \\
& (Regulador fuera de servicio). \\
\hline
\end{tabular}

De la observación del termograma de la figura 18 se deduce que la llegada del vapor saturado se efectuó cuando ya había comenzado la deshidratación del yeso, y que el primer vapor de agua desprendido por el yeso fue fijado por la cal libre, con lo cual el escalón correspondiente a la pérdida de la $1 \frac{1}{2}$ moléculas quedó disminuido en la cantidad fijada por la cal. Esto conduce a evidentes errores. De la figura 18 se deduce que el cemento contenía $27,42 \mathrm{mg}$ de yeso dihidrato y $5,97 \mathrm{mg}$ de yeso hemihidrato, cuando en realidad contenía $36,42 \mathrm{mg}$ de yeso dihidrato y nada de hemihidrato. El error relativo fue pues del $-24,7 \%$ para el dihidrato y del $100 \%$ para el hemihidrato. 
Realizando el calentamiento paulatino del agua suministradora del vapor, según el esquema del cuadro III, se obtienen los resultados mostrados en la figura 17. Puede observarse que el vapor de agua suministrado hidrata la cal libre (hidratable por vapor) antes de que empiece la deshidratación del yeso y el escalón correspondiente a la pérdida de $1 \frac{1}{2}$ moléculas de agua no sufre alteración. En consecuencia, de la figura 17 se deduce que el cemento no contiene yeso hemihidrato (de acuerdo con la realidad) y que contiene yeso dihidrato en la proporción de $34,43 \mathrm{mg}$ (contenido verdadero, 36,42 $\mathrm{mg}$ ) con error relativo del $-5,46 \%$.

\subsubsection{Mezclas yeso dihidrato-yeso hemihidrato-clínker}

Para efectuar estas mezclas se ha partido del yeso dihidrato Merck (\% pureza 86,95) y del yeso hemihidrato, obtenido en el propio termoanalizador por deshidratación en atmósfera de vapor de agua del dihidrato Merck. Se controló la deshidratación mediante el registro gráfico de la curva termogravimétrica, deteniéndose el calentamiento a $140^{\circ} \mathrm{C}$, temperatura comprendida entre la correspondiente a la pérdida de $1^{1 / 2}$ moléculas de agua y a la pérdida de $1 / 2$ molécula en atmósfera de vapor.

En la figura 19 puede verse el termograma del yeso hemihidrato obtenido. Este termograma se comenzó en atmósfera de aire con débil presión de vapor de agua (retraso en el calentamiento del agua del vaporizador) y muestra que, en esta atmósfera pobre en vapor de agua a $56^{\circ} \mathrm{C}$ ya comenzó la deshidratación del hemihidrato, elevándose notablemente la velocidad de esta deshidratación a $111^{\circ} \mathrm{C}$. El sistema de calefacción continua se conectó a $117^{\circ} \mathrm{C}$ y puede observarse en el termograma que el vapor saturado alcanzó la muestra a $124^{\circ} \mathrm{C}$, momento en que empezó la rehidratación de la anhidrita III soluble. Esta rehidratación fue completa, y entre $177^{\circ}$ y $188^{\circ} \mathrm{C}$ se verifica la pérdida de la $1 / 2$ molécula

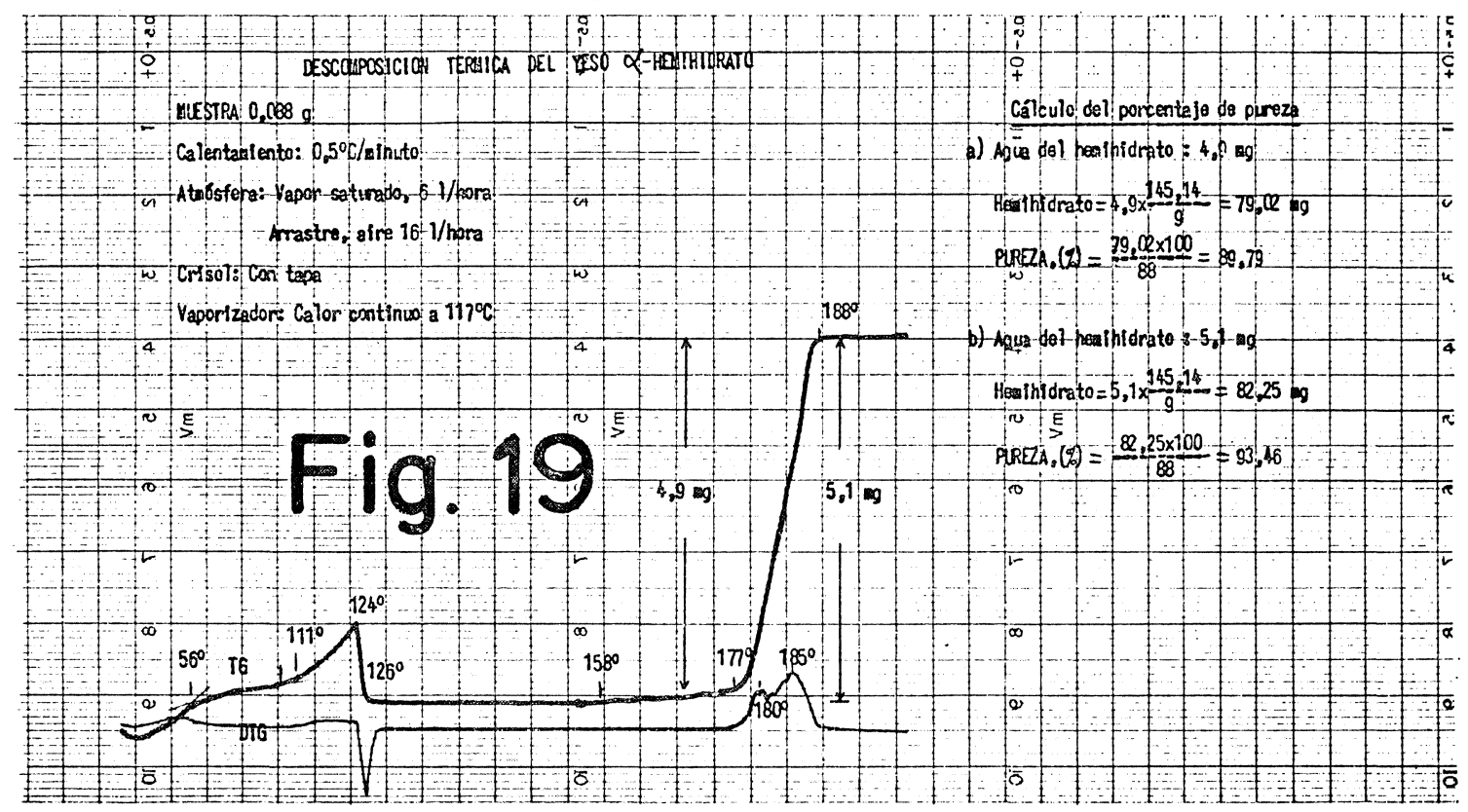


de agua del hemihidrato. A $158^{\circ} \mathrm{C}$ empieza una muy lenta pérdida de peso, aumentando la pendiente de la curva muy notablemente a $177^{\circ} \mathrm{C}$. Los resultados del cálculo del porcentaje de pureza varían según que se incluyan en el cálculo, o no, la pérdida de peso experimentada entre $158^{\circ}$ y $177^{\circ} \mathrm{C}$. No incluyendo en el cálculo esta pérdida de peso, el porcentaje de pureza resulta ser del $89,79 \%$, e incluyéndolo, del $93,46 \%$. Puede tomarse para el porcentaje de pureza el valor medio $91,62 \% \pm 1,835$.

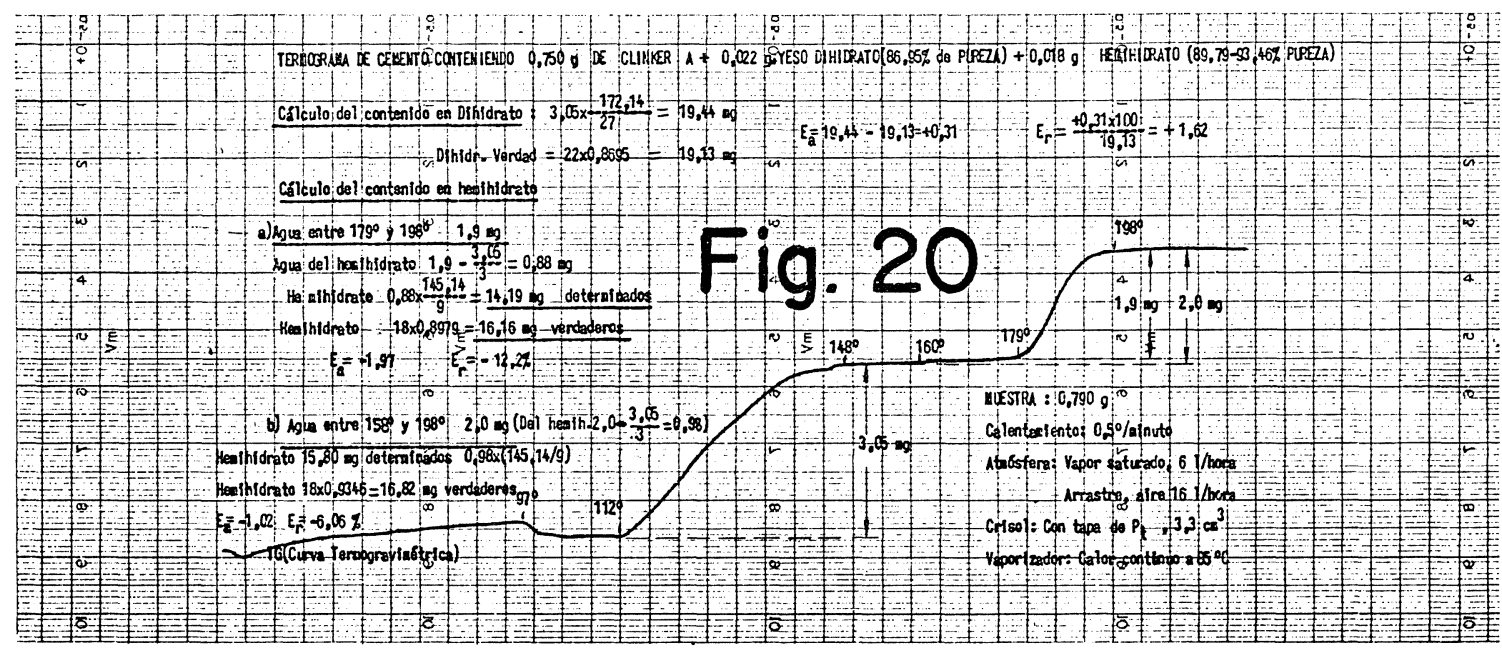

La figura 20 muestra el termograma de un cemento fabricado, en el propio crisol donde se efectuó más tarde el termoanálisis, por mezcla de los siguientes componentes:

750 mg de clínker A molido,

$22 \mathrm{mg}$ de yeso dihidrato Merck (86,95\% pureza),

$18 \mathrm{mg}$ de yeso $\alpha$-hemihidrato (89,79-93,46\% pureza).

En este termograma el calentamiento del agua del vaporizador se efectuó según el cuadro III. El cálculo de los contenidos de yeso dihidrato y hemihidrato y su comparación con las cantidades añadidas, teniendo en cuenta los porcentajes de pureza, conduce a los resultados expresados en el cuadro IV:

\section{U A D R O IV (Termograma 20)}

\begin{tabular}{|c|c|c|c|c|}
\hline \multicolumn{2}{|c|}{$M a t e r i a l e s$} & mg añadidos & mg encontrados & Error $(\%)$ \\
\hline Yeso dihidrato & $($ pureza $=86,95 \%)$ & 19,13 & 19,44 & $+1,62$ \\
\hline \multirow{2}{*}{ Yeso hemihidrato } & $\begin{array}{l}\text { - agua: } 1 / 2 \text { molécula } \\
\text { - pérdida peso: } 158^{\circ}-198^{\circ}\end{array}$ & $\begin{array}{c}16,82 \\
(\text { pureza }=93,46 \%)\end{array}$ & 15,80 & $-6,06$ \\
\hline & $\begin{array}{l}\text { - agua: } 1 / 2 \text { molécula } \\
\text { - pérdida peso: } 177^{\circ}-198^{\circ}\end{array}$ & $\begin{array}{c}16,16 \\
(\text { pureza }=89,79 \%)\end{array}$ & 14,19 & $-12,2$ \\
\hline
\end{tabular}


Finalmente en la figura 21 se muestra la curva termogravimétrica de un cemento portland comercial, al que se designa como cemento $\mathrm{C}$ y cuyo análisis químico se da en el cuadro V. Este es un tipo de curva que se encuentra con frecuencia en los cementos comerciales y presenta los dos tipos de dificultad que ya se ha señalado y que pueden conducir a error. Por un lado contiene cal libre, capaz de hidratarse con el vapor de agua o con el agua desprendida en la deshidratación del yeso, y que, como ya se vio en el caso del clínker A (figs. 17 y 18), puede conducir a error si no se hace llegar el vapor a la muestra en el momento preciso. Por otra parte, como consecuencia de la meteorización, este cemento contiene un agua, ya sea de la hidratación superficial de los silicatos y aluminatos, ya sea de una fuerte adsorción de agua sobre la superficie de los mismos, que se pierde gradualmente a las mismas temperaturas en que se deshidrata el yeso. Este último tipo de dificultad coincide con el que presenta la alúmina usada como material de dilución en nuestros primeros ensayos (fig. 16) y puede disminuirse el error que proporciona efectuando la corrección por el agua no procedente del yeso. Esta corrección se determina mediante el valor de la pérdida de peso, por unidad de tiempo, en los tramos de la curva en que no se deshidrata el yeso.

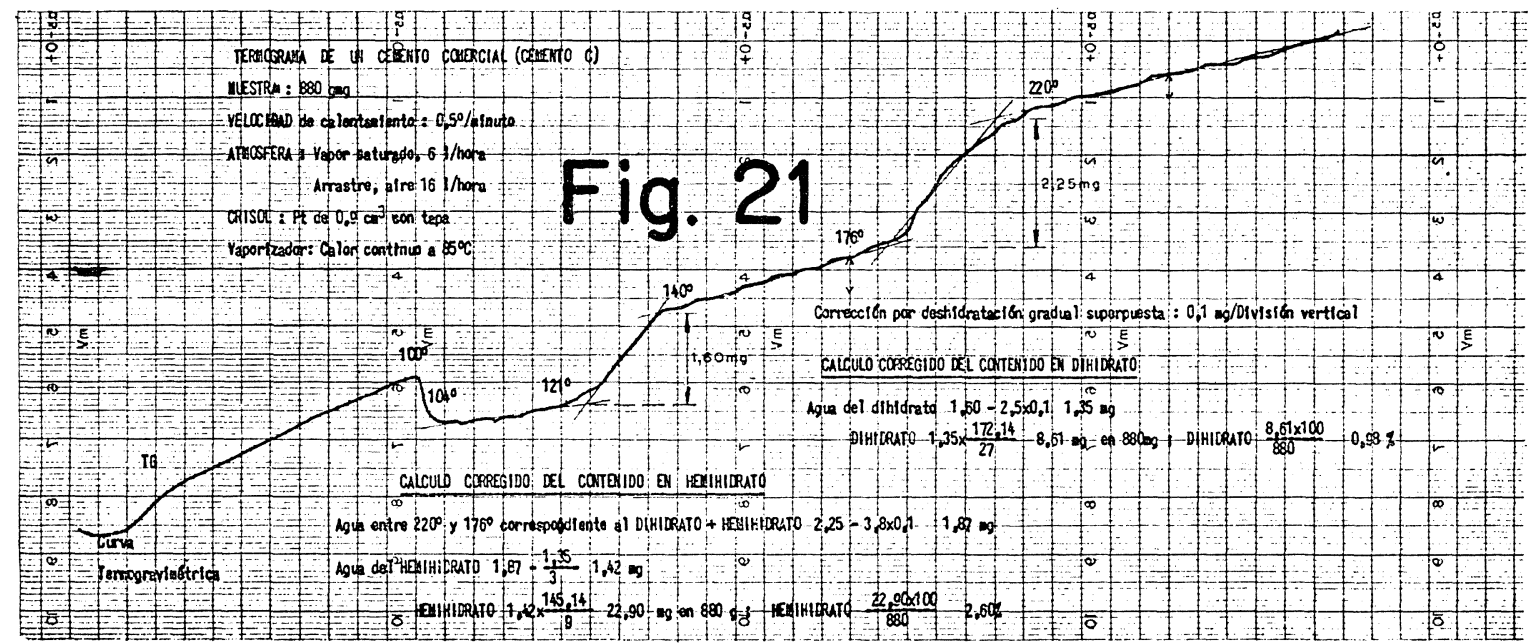

CUADRO V

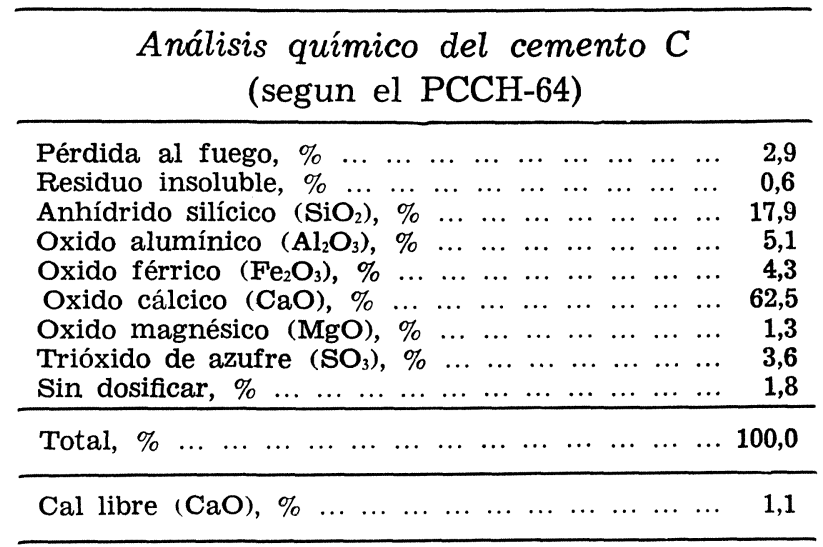




\section{CONCLUSIONES}

De los ensayos efectuados y mostrados en este trabajo puede deducirse las siguientes conclusiones:

1. ${ }^{a}$ El método termogravimétrico en atmósfera de vapor de agua es un método directo $\mathrm{y}$ adecuado para determinar las proporciones de yeso dihidrato $\mathrm{y}$ hemihidrato en los cementos.

2. $\left.{ }^{a}\right)$ Para cada termoanalizador es necesario determinar experimentalmente las condiciones de llegada del vapor saturado a las proximidades de la muestra, para que este llegue antes de que empiece la deshidratación del yeso.

3. $\left.{ }^{a}\right)$ En muchos casos se hace necesario efectuar una corrección por una pérdida de agua gradual experimentada por la muestra y que no procede del yeso.

4. ${ }^{a}$ La proporción del yeso dihidrato, en general, se determina por exceso, ya que su cálculo se efectúa a partir del escalón de pérdida de $1^{1 / 2}$ moléculas de agua, y ese escalón suele ser ligeramente mayor que el triple del escalón de la pérdida de la $1 / 2$ molécula de agua restante. El error puede ser del orden del 2 al $5 \%$. (Bernard en sus experiencias lo obtuvo por defecto y con error del 2 al $4 \%$. Esto puede ser debido a la fijación de alguna proporción de agua del dihidrato por la cal).

$\left.5{ }^{a}\right)$ La proporción de yeso hemihidrato en el cemento se determina por defecto y con mayor error que el dihidrato del -6 al $-12 \%$. (Bernard lo determina, no en el cemento, sino en mezclas dihidrato-hemihidrato, con errores de $-4 a+6 \%$ ).

En el cuadro VI se presenta un resumen de los errores con que, en nuestras experiencias, se han determinado las proporciones de yeso dihidrato $\mathrm{y}$ hemihidrato para diversos diluyentes, incluidos clínkeres.

C UADRO VI

Resumen de los errores obtenidos en la determinación de las proporciones de yeso (dihidrato-hemihidrato) mezclado con distintos diluyentes

\begin{tabular}{|c|c|c|c|c|}
\hline \multirow[t]{2}{*}{ Diluyente (mg) } & \multirow{2}{*}{$\begin{array}{l}\text { Componente determinado } \\
\text { (porcentaje aproximado) }\end{array}$} & \multicolumn{2}{|c|}{$\begin{array}{l}\text { mg de componente } \\
\text { puro en el diluyente }\end{array}$} & \multirow{2}{*}{$\begin{array}{c}\text { Error relativo } \\
(\%)\end{array}$} \\
\hline & & añadido & econtrado & \\
\hline Cuarzo molido $(600 \mathrm{mg})$ & Yeso dihidrato $(4,76 \%)$ & 26,08 & 25,82 & $-0,99$ \\
\hline Alúmina $(838,1 \mathrm{mg})$ & Yeso dihidrato $(4,76 \%)$ & 36,42 & $\begin{array}{c}33,47 \\
\text { corregido }\end{array}$ & $\begin{array}{l}-8,10 \\
(+7,66)\end{array}$ \\
\hline Clínker A $(838,1 \mathrm{mg})$ & Yeso dihidrato $(4,76 \%)$ & 36,42 & 34,43 & $-5,46$ \\
\hline Clínker A (750 mg) & $\begin{array}{l}\text { Yeso dihidrato }(2,93 \%) \\
\text { Yeso hemihidrato }(2,40 \%)\end{array}$ & $\begin{array}{l}19,13 \\
16,82\end{array}$ & $\begin{array}{l}19,44 \\
15,80\end{array}$ & $\begin{array}{l}+1,62 \\
-6,06 \% \\
(-12 \%)\end{array}$ \\
\hline
\end{tabular}

\section{B I B L I O G R A F I A}

(1) Lehmann, Mathiak y Kupiers.: Tonind. Ztg. (309-350), septiembre 1969.

(2) Claus RIeke.: Tonind. Ztg. (389-390), septiembre 1970.

(3) Gmelin-HandBuch.: CALCIUM, Teil B. Lieferung 3, pág. 723.

(4) Gmelin-Handbuch.: CALCIUM, Teil B. Lieferung 3, pág. 713.

(5) Sato y Kanaya.: Semento Gijutsu Nempo (70-77), n.o 16, 1962.

(6) Bensted y VARna.: Cement Technology. marzo-abril 1972.

(7) D. A. St. John.: New-Zealand Jour. Sc. (353-361), mayo 1964.

(8) C. J. Keatch.: J. Appl. Chem. (London) 17, 27-28, 1967.

(9) Bernard.: Bull Liaison Lab. Routiers, Special 0-130 1970. 